
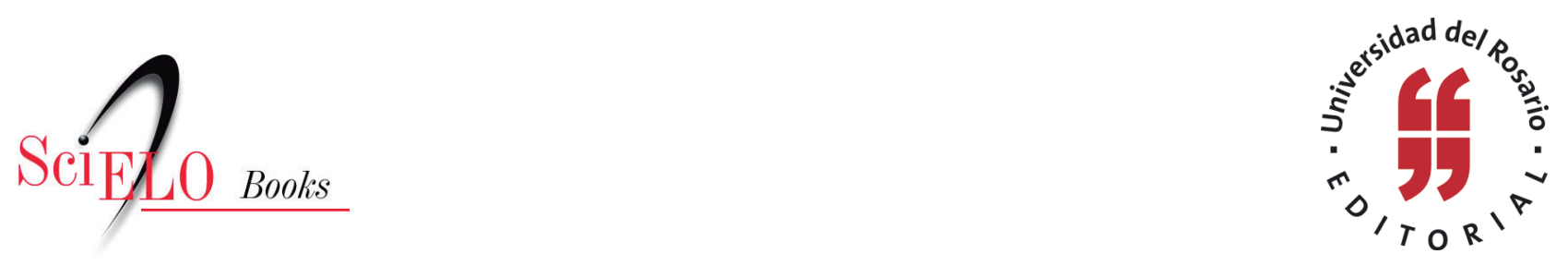

\title{
Capítulo tercero \\ Alcance de los postulados solidaristas en Colombia en la década de 1930
}

\author{
Ana Carolina Mercado Gazabón
}

\section{SciELO Books / SciELO Livros / SciELO Libros}

MERCADO GAZABÓN, A.C. Alcance de los postulados solidaristas en Colombia en la década de 1930. In: La influencia de León Duguit en la reforma social de 1936 en Colombia: el sistema jurídico, la función social de la propiedad y la teoría de los servicios públicos [online]. Bogotá: Editorial Universidad del Rosario, 2015, pp. 35-63. Textos de Jurisprudencia collection, Maestría serie. ISBN: 978-958-738-638-7. https://doi.org/10.7476/9789587386387.0005.

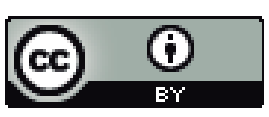

All the contents of this work, except where otherwise noted, is licensed under a Creative Commons Attribution 4.0 $\underline{\text { International license. }}$

Todo o conteúdo deste trabalho, exceto quando houver ressalva, é publicado sob a licença Creative Commons Atribição $\underline{4.0}$.

Todo el contenido de esta obra, excepto donde se indique lo contrario, está bajo licencia de la licencia $\underline{\text { Creative }}$ Commons Reconocimento 4.0. 


\section{Capítulo tercero \\ Alcance de los postulados solidaristas en Colombia en la década de 1930}

En la búsqueda de textos de los años treinta y sus alrededores se han encontrado interesantes escritos de intelectuales de las primeras tres décadas del siglo xx en torno a la obra de León Duguit, de ellos se hará constante uso en este capítulo, amén de desear contribuir al redescubrimiento de nuestro pasado histórico jurídico.

Como se expresó en la introducción y en el primer capítulo, se ha hallado una conferencia que data del año 1927 y que fue publicada en el número 200 de la Revista Jurídica, suscrita por Marco Naranjo López, en la que se resumió la teoría del profesor francés, sintetizándola en cuatro grandes temas: la regla de derecho, el fundamento de la regla de derecho, la función social y el servicio público. Así inicia el citado escrito:

León Duguit, como ustedes lo saben, decano de la Facultad de Derecho de la Universidad de Burdeos, emprendió hace más de veinte años la revaluación de las doctrinas jurídicas y de las legislaciones vigentes en seria acometida revolucionaria. $Y$ hace también más de veinte años que es combatido por los jurisconsultos de nuestro tiempo. De anarquista se le trata algunas veces, determinista, plagiario etc. Yo no quiero adoptar ninguna actitud agresiva ante las teorías del profesor bordelés, porque mi juventud me inclina naturalmente a la comprensión y al análisis sereno.

También se ha encontrado un texto publicado en el año 1935 titulado Critica del derecho constitucional (Exposición sistemática del derecho constitucional de León Duguit), cuya autoría es de Juan Francisco Forero. Poco se ha hallado de este autor, pero existe certeza que su obra gozaba de prestigio. El comentarista de la reforma de 1936, José Gnecco Mozo, quien, bajo el título 
Bibliografía constitucional colombiana, dedicó las últimas páginas de su texto a evocar a los constitucionalistas de los siglos XIX y XX, alude a los estudios de Juan Francisco Forero N. en los siguientes términos: "Recientemente han sido publicadas: la Crítica del Derecho Constitucional por Juan Francisco Forero N., síntesis de divulgación de las teorías de León Duguit [...]”.1

Se trata de un libro que en tres segmentos resume los postulados del decano de Burdeos. En palabras del autor: "Esta introducción se divide en tres partes que constituyen, de cierta manera, una tríada lógica; en la primera parte, se trata del derecho en general; en la segunda, del poder político; en la tercera del derecho público, esto es, del derecho en cuanto rige al poder político". ${ }^{2}$

Del administrativista Carlos H. Pareja, de quien no deja de sorprender no haya merecido en nuestro país una mayor atención, su obra Derecho administrativo teórico y práctico (1937) se constituye en otro texto de importante estimación.

Los escritos en mención serán herramienta útil en nuestro propósito de demostrar la influencia concreta del autor en la reforma.

\section{El sistema jurídico}

Para resolver el problema del derecho se debe partir de la sociedad y no unicamente del individuo Juan Francisco Forero N.

Enarboló el Estado liberal-burgués como banderas, el individualismo, ${ }^{3}$ al establecer garantías y seguridades a la libertad personal (derechos civiles y políticos), en ese orden de ideas, se reconocieron e incorporaron derechos

${ }^{1}$ Gnecco Mozo, José. La reforma constitucional de 1936. Bogotá: ABc, 1938, p. 332.

${ }^{2}$ Forero N., Juan Francisco. Crítica del derecho constitucional. Bogotá: Minerva, 1935, s.p.

${ }^{3}$ Los derechos naturales y la libertad individual como principio se encuentran formulados en los artículos 1, 2 y 4 de la Declaración Universal Francesa de los Derechos del Hombre y del Ciudadano de 1789:

"Artículo 1o. Los hombres nacen y permanecen libres e iguales en derechos. Las distinciones sociales sólo pueden fundarse en la utilidad común.

Artículo 2o. La meta de toda asociación política es la conservación de los derechos naturales e imprescriptibles del hombre. Estos derechos son: la libertad, la propiedad, la seguridad y la resistencia a la opresión.

Artículo 4o. La libertad consiste en poder hacer todo lo que no daña a los demás.

Así, el ejercicio de los derechos naturales de cada hombre no tiene más límites que los que aseguran a los demás miembros de la sociedad el goce de estos mismos derechos. Estos límites sólo pueden ser determinados por la ley". 
individuales como una exaltación del hombre, pero a la vez como un límite al poder del Estado, a la arbitrariedad de las autoridades, ejemplos de estas libertades individuales lo eran la libertad de opinión, la protección contra la privación arbitraria de la libertad — denominada por la tradición inglesa habeas corpus - la inviolabilidad del domicilio, la protección contra registros y confiscaciones ilegales, la libertad de la actividad económica, de elección de profesión, de competencia, de libre disposición sobre la propiedad, el derecho a votar y de tener igual acceso a todos los cargos, entre otros.

La reforma de 1936 introdujo un importante cambio en el ordenamiento colombiano, al derogar expresamente el artículo 19 de la Constitución de $1886^{4}$ y esa trascendental variación es la desaparición del sistema jurídico iusnaturalista, entendido este en un sentido absoluto. ${ }^{5}$

La noción puramente subjetiva e individualista del derecho según la cual el hombre era, por naturaleza, libre, independiente, aislado, propietario de derechos individuales, inalienables e imprescriptibles, llamados naturales y que se encontraban indisolublemente unidos a su cualidad de hombre, se desvaneció e hizo su aparición una concepción social del mismo que niega la existencia de los derechos naturales ilimitados y se fundamentó en el realismo y objetivismo jurídico, en la interacción y solidaridad social. Bajo esa premisa, no hubo en el ordenamiento jurídico colombiano, en lo sucesivo, derechos naturales absolutos sino derechos considerados como funciones y obligaciones sociales, y el medio para garantizarlos fue la intervención del Estado.

4 “Artículo 34 Acto Legislativo 01 de 1936: Quedan expresamente derogación los artículos 4o (en sus tres últimos incisos), $8^{\circ}, 9^{\circ}, 11,12,14,15,16,17,18,19,31,32,36,38,39,40,41,43,49,50,53,55$, 56, 57, 58 (inciso $2^{\circ}$ ) , 59, 60, 64, 91, 111, 135 y 172 de la Constitución Nacional; $1^{\circ}, 2^{\circ}, 5^{\circ}, 8^{\circ}, 23,43$ y 44 del Acto legislativo número $3^{\circ}$ de 1910, y el Acto legislativo número 1 de 1932; y modificados los artículos 37, 47 (incisos $1^{\circ}$ y 30), 88 y 90 (en lo relativo al 88) de la Constitución, 21 del Acto legislativo número 3 de 1910 y 4º del Acto legislativo número 1 de $1930 "$.

${ }^{5}$ Desde 1934 Tascón, en su texto de Derecho constitucional colombiano, criticaba este artículo catalogándolo como la "cifra y compendio de la doctrina individualista" y señalando que "Estimar que la función esencial del Estado es mantener represivamente el orden jurídico, protegiendo los llamados derechos naturales mediante la prevención y castigo de los delitos, equivale a reducir las funciones del Estado a la simple policía o a la prestación del servicio público de justicia. El artículo nada dice de la intervención del Estado en la satisfacción de las necesidades humanas; nada de la misión del estado como órgano defensivo de las libertades individuales; nada de las obligaciones positivas del Estado" (Resaltado fuera de texto). Tascón, Tulio Enrique. Derecho constitucional colombiano. Comentarios a la Constitución Nacional. Bogotá: Minerva, 1934, p. 72. 
De conformidad con lo expuesto, con la reforma constitucional de 1936, se da por superado lo que Juan Francisco Forero N. planteaba en su obra (publicada en 1935) como El problema del derecho; ¿era subjetivo?, ¿fundamentado en la naturaleza del hombre? O, más bien, ¿objetivo, fundamentado en la naturaleza de la sociedad? El mismo autor resolvía el cuestionamiento en ese momento, anticipándose al texto de la enmienda y con apego a la teoría de Duguit, manifestando que "El derecho es una regla de conducta que se impone a los hombres que viven en sociedad y engendra situaciones jurídicas. Tiene por fundamento la sociedad o, mejor aún, la solidaridad social. No existen derechos subjetivos sino derecho objetivo y situaciones jurídicas". ${ }^{6}$ Para el mismo autor "las concepciones subjetivistas sobre la naturaleza del derecho y las teorías individualistas sobre el fundamento del derecho eran aceptadas antiguamente en el derecho público y en el derecho privado como dogmas intangibles, pero hoy día debido a las transformaciones profundas del mundo moderno, el subjetivismo y el individualismo se muestran impotentes; se puede decir que el paso del subjetivismo al objetivismo jurídico y del individualismo al socialismo forma la característica esencial de la evolución jurídica del primer cuarto del siglo xx". ${ }^{7}$

Ahora bien, el supuesto del cual se partía para esa transición de un esquema subjetivo de derecho a uno objetivo fue la consideración duguitiana según la cual el hombre era un ser social y no podía vivir sino en sociedad.

Por su parte, sobre el particular, enseñaba en 1927 Marco Naranjo López, que al interior de la sociedad una regla de conducta se impone a los individuos, estos tienen

[...] una cierta función que cumplir, una cierta tarea que ejecutar. Y este es precisamente el fundamento de la regla de derecho que se impone a todos, grandes y pequeños, gobernantes y gobernados [...] E1 hombre, no tiene derechos subjetivos; no puede tenerlos porque un derecho es una abstracción sin realidad, pero por lo mismo que es miembro de una sociedad, tiene la obligación de hecho de cumplir una cierta función, y los actos que realiza para este fin tienen un valor social y serán socialmente protegidos. ${ }^{8}$

${ }^{6}$ Forero N. Op. cit., p. 38.

${ }^{7}$ Ibid., p. 20-21.

8 Duguit, León. Lecciones de derecho público general. Madrid: Marcial Pons, 2011, p. 178 y ss. 
Volviendo al texto de la reforma se tiene que de una interpretación sistemática de los artículos 10,13,14,15 y 17, arriba transcritos, se advierte que el constituyente del 36 adoptó un fundamento solidarista de las libertades, en el sentido de que son entendidas para sus titulares como deberes, en ese orden de cosas, los miembros de una sociedad están obligados a desenvolver actividades para que sus derechos sean compatibles con la sociedad, verbigracia, deben instruirse, deben trabajar, deben emplear lo que poseen en provecho de la sociedad o lo que es lo mismo ejercer el derecho de dominio bajo una perspectiva social, en fin, desarrollar sus actividades físicas, intelectuales o morales. Sobre el papel de los gobernados en el mundo del individualismo y en el de Duguit, señalaba Forero N. en su texto:

En la teoría individualista el libre desarrollo de las actividades individuales constituye un derecho natural intangible; en la teoría duguitiana constituye un deber o una función social. En la teoría individualista el individuo puede a su antojo, desenvolver o no desenvolver sus facultades individuales, en la teoría duguitiana debe forzosamente desenvolverlas. En la teoría individualista las personas pueden instruirse o no instruirse, trabajar o no trabajar, usar sus cosas en bien propio y de la sociedad o no usarlas, etc.; en la teoría duguitiana las personas deben instruirse, deben trabajar, deben emplear lo que poseen en bien de la colectividad y si no lo hacen, si no cumplen con esos deberes, el Estado puede obligarlas". ${ }^{9}$

Sobre el particular, con posterioridad a la reforma, expresaba Carlos $\mathrm{H}$. Pareja: "En virtud de esa transformación que ha estudiado ampliamente Duguit, los derechos civiles clásicos han dejado de ser medios de acción puestos al servicio del individuo para su servicio personal y se han convertido en instrumentos de servicio público". ${ }^{10}$

Aparte de ello, la solidaridad también obliga a los gobernantes, en ese orden de ideas, al decir de Duguit "La solidaridad se impone también a los órganos públicos, al estar éstos sometidos al Derecho. E1 Estado refleja la contraposición entre gobernantes y gobernados, pero los gobernantes no son

${ }^{9}$ Forero N. Op. cit., p. 224 y ss.

${ }^{10}$ Pareja, Carlos H. Derecho administrativo teórico y práctico. Bogotá: ABC, 1937, p. 19. 
considerados como instancias superiores a los gobernados; la solidaridad se impone a todos y los gobernantes deben utilizar su potestad pública para asegurar el respeto al interés general". ${ }^{11}$ Entonces, los gobernantes tienen obligaciones negativas y obligaciones positivas, en ese sentido, en primer lugar, no deben hacer nada que contraríe la solidaridad, pero, adicionalmente, deben hacer todo lo posible por favorecerla, es decir que "los gobernados están obligados a desarrollar sus actividades individuales, y los gobernantes como poseedores del poder político, están obligados no solamente a no hacer nada en contra de ellas sino a favorecerlas", ${ }^{12}$ y allí radica la diferencia con la teoría individualista en la que el Estado tenía solamente obligaciones negativas.

El constituyente J.J. Caicedo Castilla se expresaba así sobre el contenido del artículo 9 de la reforma:

Reemplaza al 19 de la Constitución que consagraba la más absoluta teoría individualista: la del Estado-gendarme, que no podía intervenir para la satisfacción de las necesidades humanas o para la defensa de las libertades, o para realizar las necesidades colectivas. Nada hablaba el artículo de las obligaciones positivas del Estado, de sus deberes sociales [...] Es una reforma doctrinaria de grande importancia, porque permite orientar las actividades del Estado en un sentido intervencionista favorable al bienestar común (Resaltado del texto). ${ }^{13}$

En el mismo sentido, Timoleón Moncada, en uno de sus discursos en el Senado expresó:

La Constitución del 86 estaba fundada en la escuela individualista que tuvo su fórmula precisa, tomada de la declaración de los derechos del hombre de 1789 y que se concreta así: "los hombres nacen y permanecen libres e iguales en derecho. [...] Pero la escuela individualista, que tuvo su época gloriosa, que fue necesaria en su tiempo, ha dejado de existir en el mundo entero, $y$ ha dejado también en Colombia.

\footnotetext{
${ }^{11}$ Monereo Pérez y Calvo González. La teoría jurídica de León Duguit. En: Calvo González. Manual de Derecho Constitucional. Granada: Comares, 2005, en el estudio preliminar.

${ }^{12}$ Forero N., Op. cit., p. 224.

${ }^{13}$ Citado por Gnecco Mozo. Op. cit., p. 135 y ss.
} 
Este artículo 9 es de gran trascendencia: sustituyó la base fundamental del individualismo de la Constitución del 86 por las ideas del derecho social". ${ }^{14}$

Entre las obligaciones positivas del Estado figuran las de asistir, enseñar, procurar trabajo, lo que resulta acorde con el contenido de los artículos 9, 11, 13, 14, 16 y 17 del Acto Legislativo 01 de 1936 sobre deberes del Estado, intervención del Estado, libertad de conciencia, libertad de enseñanza, asistencia pública y derecho al trabajo.

Un nuevo cuadro comparativo, entre lo que finalmente quedó contenido en la reforma y las apreciaciones que sobre esos derechos dio el autor colombiano, Forero N., seguidor de las teorías de Duguit, permitirán apreciar mejor la influencia de los postulados del catedrático de Burdeos en la reforma en estudio:

Tabla 1. Reforma y apreciaciones sobre los deberes y la intervención del Estado, las libertades de conciencia y de enseñanza, la asistencia pública y el derecho al trabajo

\begin{tabular}{|c|c|}
\hline Acto Legislativo no 01 de 1936 & $\begin{array}{c}\text { "Las obligaciones del Estado" en la obra de } \\
\text { Juan Francisco Forero N. }\end{array}$ \\
\hline $\begin{array}{l}\text { Artículo 13. E1 Estado garantiza la libertad de } \\
\text { conciencia. } \\
\text { Nadie será molestado por razón do sus opiniones } \\
\text { religiosas, ni compelido a profesar creencias ni a } \\
\text { observar prácticas contrarias a su conciencia. } \\
\text { Se garantiza la libertad de todos los cultos, que } \\
\text { no sean contrarios a la moral cristiana ni a las } \\
\text { leyes. Los actos contrarios a la moral cristiana o } \\
\text { subversivos del orden público, que se ejecuten con } \\
\text { ocasión o pretexto del ejercicio de un culto, quedan } \\
\text { sometidos al derecho común. } \\
\text { El Gobierno podrá celebrar con la Santa Sede } \\
\text { convenios sujetos a la posterior aprobación del } \\
\text { Congreso para regular, sobre bases de recíproca } \\
\text { deferencia y mutuo respeto, las relaciones entro el } \\
\text { Estado y la Iglesia Católica. }\end{array}$ & $\begin{array}{l}\text { ¿Cuál es la actitud que debe adoptar el Estado frente } \\
\text { a la religión? } \\
\text { a) Cuando la religión es una cosa individual } \\
\text { y privada, como acontece hoy día en la } \\
\text { mayor parte de los países, el Estado debe } \\
\text { permanecer neutral: no debe reconocer } \\
\text { ni retribuir ningún culto, tan solo puede } \\
\text { intervenir para que las manifestaciones del } \\
\text { culto de algunos no atente a la libertad de } \\
\text { los demás. En este caso para el Estado no } \\
\text { hay judíos, ni musulmanes, ni budistas, } \\
\text { etc.,sino nacionales, o mejor aún, hombres } \\
\text { cuyas creencias se les debe respetar [...]. }{ }^{15}\end{array}$ \\
\hline
\end{tabular}

Continúa

${ }^{14}$ Ibid., p. 136.

15 Forero N., Op. cit., p. 211. Para el comentarista de la reforma del 36 Gnecco Mozo, "En esta disposición se echó abajo la primacía que la Constitución anterior le daba a la Iglesia Apostólica, Católica y Romana sobre las demás religiones [...] En una palabra, la reforma tiende a sacar de la Constitución las relaciones especiales con la Santa Sede y dejarlas únicamente en el campo de las relaciones internacionales, en donde se podrá pactar con más libertad en lo futuro". Gnecco Mozo. Op. cit., p. 186. 


\begin{tabular}{|c|c|}
\hline Acto Legislativo no 01 de 1936 & $\begin{array}{l}\text { "Las obligaciones del Estado" en la obra de } \\
\text { Juan Francisco Forero N. }\end{array}$ \\
\hline $\begin{array}{l}\text { Artículo 14. Se garantiza la libertad de enseñan- } \\
\text { za. El Estado tendrá, sin embargo, la suprema } \\
\text { inspección y vigilancia de los institutos docentes, } \\
\text { públicos y privados, en orden a procurar el cum- } \\
\text { plimiento de los fines sociales de la cultura y la } \\
\text { mejor formación intelectual, moral y física de los } \\
\text { educandos. } \\
\text { La enseñanza primaria será gratuita en las es- } \\
\text { cuelas del Estado, y obligatoria en el grado que } \\
\text { señalo la ley. }\end{array}$ & $\begin{array}{l}\text { El Estado debe }[\ldots] \text { tomar las medidas necesa- } \\
\text { rias para que todo establecimiento de enseñanza } \\
\text { presente condiciones de salubridad y moralidad; } \\
\text { debe ejercer un control sobre los maestros para } \\
\text { impedir que atenten a la libertad física, intelectual } \\
\text { o moral de sus alumnos, debe exigir condiciones de } \\
\text { capacidad profesional, pedagógica o científica, a las } \\
\text { personas que quieran enseñar o abrir una escuela; } \\
\text { puede también establecer una enseñanza primaria } \\
\text { obligatoria pues esta favorece el desarrollo de las } \\
\text { actividades individuales, etc. }{ }^{16} \\
\text { El estado debe organizar una enseñanza primaria } \\
\text { gratuita y puede imponer a todos los miembros } \\
\text { de la sociedad la adquisición de un mínimum de } \\
\text { instrucción, pues ello contribuye al conveniente } \\
\text { desenvolvimiento de las actividades individuales, } \\
\text { factor importantísimo de la solidaridad social. }{ }^{17}\end{array}$ \\
\hline $\begin{array}{l}\text { Artículo 16. La asistencia pública es función del } \\
\text { Estado. Se deberá prestar a quienes careciendo de } \\
\text { medios de subsistencia y de derecho para exigirla } \\
\text { de otras personas, estén físicamente incapacitados } \\
\text { para trabajar. } \\
\text { La ley determinará la forma como se preste la } \\
\text { asistencia y los casos en que deba darla directa- } \\
\text { mente el Estado. }\end{array}$ & $\begin{array}{l}\text { El Estado debe asistir a las mujeres parturientas, } \\
\text { debe proteger a los niños, debe asegurar la sub- } \\
\text { sistencia a las familias numerosas, debe procurar } \\
\text { a las personas inválidas o enfermas los medios de } \\
\text { curarse o de subsistir, si son incurables, etc. }{ }^{18}\end{array}$ \\
\hline $\begin{array}{l}\text { Artículo 17. El trabajo es una obligación social y } \\
\text { gozará de la especial protección del Estado. }\end{array}$ & $\begin{array}{l}\text { El Estado está obligado a procurar trabajo a las } \\
\text { personas que quieran trabajar y no encuentren } \\
\text { trabajo; de otro modo esas fuerzas de trabajo no } \\
\text { podrían contribuir al desarrollo de la interdepen- } \\
\text { dencia social. El Estado está también obligado a } \\
\text { reglamentar el trabajo y a proteger al trabajador } \\
\text { porque es inadmisible que el trabajador sea explo- } \\
\text { tado por su patrón y obligado a aceptar salarios de } \\
\text { hambre o hacer trabajo superiores a sus fuerzas. }{ }^{19}\end{array}$ \\
\hline
\end{tabular}

Fuente: Elaboración propia basada en el Acto Legislativo y la obra de Forero N.

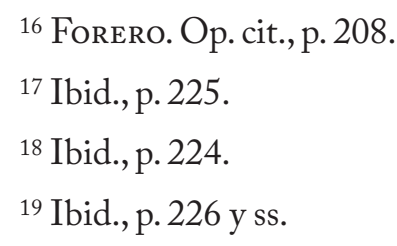




\title{
II. La "cuestión social" en la propiedad
}

\author{
Ni derechos del individuo, ni derechos del Estado, eso es pura \\ metafísica inventada o seguida por los individualistas en \\ época de extravio \\ Marco Naranjo López
}

La concepción de la propiedad sería otro de los puntos importantes de la reforma de 1936, pues se trataba de romper la teoría del liberalismo clásico, hasta ese entonces imperante en el país, según la cual la propiedad era un derecho natural, por una nueva noción en la que esta tendría una función social.

De acuerdo con el individualismo propio del Estado liberal-burgués, el Estado debía intervenir de forma limitada en el plano económico, pensamiento expresado en la célebre fórmula del laissez faire, laissez passer, que inspiró a los economistas ingleses de la época, particularmente a Adam Smith y David Ricardo. ${ }^{20}$ Un mínimo de gobierno, un máximo de libertad resume este pensamiento. El papel del Estado es reducido: el de un simple gendarme.

De conformidad con ello, la santificación de la propiedad privada legitimó un nuevo orden económico, el del laissez faire. Los artículos 17 de la Declaración Francesa de 1789 y 544 del Código de Napoleón denotan los alcances de este derecho en la era del liberalismo puro. La primera dispuso:

Siendo la propiedad un derecho inviolable y sagrado, nadie puede ser privado de ella sino cuando la necesidad pública, legalmente constatada, lo exige claramente y con la condición de una indemnización justa y previa (Resaltado fuera de texto).

20 "El pensamiento liberal también tuvo una expresión particular en el campo de la ciencia económica. Los economistas ingleses Adam Smith y David Ricardo son los fundadores del llamado sistema clásico en la historia de las doctrinas económicas. Su mayor mérito consistió en haber puesto orden en el Estado entonces caótico de la investigación económica y en haber ofrecido por primera vez una explicación científica completa del proceso económico, en la cual se exponen rigurosamente las leyes y principios subyacentes al funcionamiento del sistema capitalista individualista así como el proceso histórico que le dio origen [...] Por eso se opone Smith a todas la formas de intervención del Estado en los negocios ordinarios de la industria y el comercio; es un paladín del laissez faire, laissez passer [...] la conservación de la libre competencia es el principal deber de la política económica [...] El Estado, como si fuera un gendarme, se debe limitar a vigilar el campo social e intervenir solo en la medida de lo necesario para proteger los derechos de los individuos". Hernández Becerra, Augusto. Las ideas políticas en la historia. Bogotá: Universidad Externado de Colombia, 1997, p. 281 y ss. 
Por su parte, el Código de Napoleón consignó que "la propiedad es el derecho de disfrutar y disponer de las cosas de la manera más absoluta, en tanto no se haga de ellos un uso prohibido por las leyes y los reglamentos".

Tal fue la relevancia dada a este derecho que "la Convención francesa de 1793 no se contentó con esto sólo; llegó hasta decretar la pena de muerte contra cualquier ciudadano que propusiera una ley agraria u otra cualquiera subversiva de las propiedades territoriales, comerciales o industriales". ${ }^{21}$

Por otro lado, el ordenamiento constitucional colombiano aceptaría en las Cartas del siglo XIX tal concepción del dominio, ${ }^{22}$ merece destacarse la de 1886 toda vez que es esta la que fue objeto de modificación mediante el Acto Legislativo no 01 de 1936:

\begin{abstract}
Artículo 32. En tiempo de paz nadie podrá ser privado de su propiedad en todo ni en parte, sino por pena, o apremio, o indemnización, o contribución general, con arreglo a las leyes. Por graves motivos de utilidad pública, definidos por el Legislador, podrá haber lugar a enajenación forzosa, mediante mandamiento judicial, y se indemnizará el valor de la propiedad, antes de verificar la expropiación
\end{abstract}

${ }^{21}$ Forero N., Op. cit., p. 215.

${ }^{22}$ La Constitución de Cúcuta de 1821 consagró en sus “Disposiciones Generales”(Título VII) la propiedad privada: “Artículo 177: Ninguno podrá ser privado de la menor porción de su propiedad, ni ésta será aplicada a usos públicos, sin su propio consentimiento, o el del Cuerpo Legislativo; cuando alguna pública necesidad legalmente comprobada exigiere que la propiedad de algún ciudadano se aplique a usos semejantes, la condición de una justa compensación debe presuponerse”. La Constitución de 1830, en el Título XI "De los derechos civiles y las garantías" contiene el siguiente artículo sobre propiedad privada: "Artículo 146. Ningún colombiano puede ser privado de su propiedad ni esta aplicada a ninguno uso público, sin su consentimiento. Cuando el interés público, legalmente comprobado así lo exija, el propietario recibirá previamente una justa compensación”. La Constitución de 1832 la consagró en el artículo 193: “A excepción de las contribuciones establecidas con arreglo a esta constitución o a las leyes, ningún granadino será privado de la menor porción de su propiedad, ni ésta aplicada a ningún uso público sin su propio consentimiento. Cuando alguna pública necesidad legalmente comprobada, exigiere que la propiedad de algún granadino se aplique a usos semejantes, la condición de una justa compensación debe presuponerse”. El Texto Político de 1843, dispuso, en el artículo 162 “A excepción de las contribuciones establecidas por ley, ningún granadino será privado de parte alguna de su propiedad para aplicarla a usos públicos, sin su libre consentimiento; a menos que alguna pública necesidad, calificada tal con arreglo a la ley, así lo exija, en cuyo caso debe ser indemnizado de su valor". Por su parte, la Constitución de la Nueva Granada de 1853, en su artículo quinto reseñó un listado de garantías entre las que se encuentra la propiedad. Posteriormente, la Constitución de 1858, en su artículo 56, reconoció a todos los habitantes y transeúntes la propiedad. La Constitución de Rionegro, en el artículo 15, incluyó a la propiedad como uno de sus derechos más importantes. 
Artículo 33. En caso de guerra y sólo para atender al restablecimiento del orden público, la necesidad de una expropiación podrá ser decretada por autoridades que no pertenezcan al orden judicial y no ser previa la indemnización.

En el expresado caso la propiedad inmueble sólo podrá ser temporalmente ocupada, ya para atender a las necesidades de la guerra, ya para destinar a ella sus productos, como pena pecuniaria impuesta a sus dueños conforme a las leyes.

La Nación será siempre responsable por las expropiaciones que el Gobierno haga por sí o por medio de sus agentes.

Las normas civiles también apadrinaron el esquema liberal, desde la construcción de un arquetipo en el que la propiedad constituía un derecho absoluto de disposición, cuya máxima garantía estaba en la facultad del titular de usar, gozar y disponer al mejor estilo del dominium romano. Bajo este entendido, el artículo 669 del cc dispuso que la propiedad es "un derecho real en una cosa corporal, para gozar y disponer de ella arbitrariamente, no siendo contra ley o contra derecho ajeno".

Sostenía Tascón, al referirse a la norma transcrita, que

[...] este concepto de la propiedad como un derecho absoluto tiende a modificarse actualmente, para convertir la propiedad en una función social. En donde quiera, las leyes obligan al dueño de las tierras a ponerlas en cultivo, al dueño de solares urbanos a edificar en ellos, etc., pues se estima que el título de propietario implica la obligación de emplear la riqueza detentada en aumentar la riqueza general y contribuir con ello al bienestar común como un deber de solidaridad social. ${ }^{23}$

Bajo este escenario, debe decirse que existía en el país un anhelo de reforma al texto de 1886. En el ambiente político, desde 1931, Jorge Eliécer Gaitán y otros parlamentarios habían presentado un proyecto de enmienda sobre el particular que, aunque fue archivado, mostraba la intención por el cambio en materia de propiedad privada.

${ }^{23}$ TAscón. Derecho constitucional... Op. cit., p. 92. 
Como antecedente inmediato de la reforma debe señalarse que en el año 1934, se presentó un Proyecto de Acto Legislativo reformatorio de la Constitución "por el cual se sustituyen los Artículo 31 de la misma y 5 del Acto Legislativo 3 de 1910”, en la exposición de motivos, y refiriéndose al régimen de propiedad, Darío Echandía criticaba la noción subjetiva y absolutista de la propiedad, cuyo ejercicio llega hasta el abuso en el hacer y en el no hacer uso de él, esto es "en que pueda quemar mi casa en aras del ius abutendi, impunemente, en que puedo dejar mi solar urbano perpetuamente sin edificarlo". ${ }^{24}$

En esa ocasión, el Congreso no aceptó los argumentos del Ministro Echandía para modificar lo relacionado con el régimen de propiedad. A pesar de ello, se advierte claramente la postura teórica en la cual se encontraba inscrito el gobierno de Alfonso López Pumarejo, a través de su vocero gubernamental, que vendría a ser insistida hasta el éxito por sus proponentes un año después.

En la doctrina, el citado Juan Francisco Forero N., en 1935, también hacía su propuesta de reforma en los siguientes términos:

Antiguamente la propiedad tenía por objeto favorecer la apropiación de las riquezas con fines individuales, y para ello era suficiente, aunque inexacto, considerar a la propiedad como un derecho natural, subjetivo y absoluto, pero hoy día como tiene por objeto favorecer la apropiación de las riquezas con fines no solo individuales sino esencialmente colectivos, esa concepción debe ser reemplazada por la concepción de la propiedad como una función social [...] En conclusión, la concepción individualista de la propiedad, inexacta pero suficiente para satisfacer las necesidades económicas de los tiempos pasados, debe ser reemplazada por una concepción socialista (o del derecho social) exacta y de acuerdo con las necesidades económicas de los tiempos presentes, ${ }^{25}$

Y recurrió en su texto a la experiencia del derecho comparado, pues ya muchos países consideraban la propiedad como una función social: En Francia la ley Briand sobre asociaciones para el culto, las leyes sobre hilos telegráficos y telefónicos, sobre propiedad del aire; en Dantzig los artículos 111 y 112

\footnotetext{
${ }^{24}$ Colombia. Congreso de la República, Proyecto Acto legislativo, 1934.

${ }^{25}$ For ero N., Op. cit., p. 218-219.
} 
de la Constitución ${ }^{26}$ restringían el dominio; del mismo modo el artículo 99 de la Constitución de Polonia limitaba la propiedad ${ }^{27}$ y la ley sobre organización económica, comercial y profesional de la Ciudad del Vaticano hacía lo suyo. Los artículos 153 de la Constitución alemana ${ }^{28}$ y 37 de la de Yugoeslavia ${ }^{29}$ eran otros ejemplos expuesto por el autor. Lo cierto era que las Constituciones mexicana de $1917^{30}$ y alemana de Weimar de $1919^{31}$ ya lo habían consagrado y eran un referente conocido en nuestro territorio.

Finalmente, fue López Pumarejo quien logró, con la aprobación del texto de la reforma no 01 de 1936, la realización de este anhelo de dotar al dominio de un contenido social, a fin de lograr una adecuada explotación del suelo agrario y su redistribución entre un número mayor de agricultores. El texto aprobado, artículo 10 de la enmienda, fue, según Gnecco Mozo, "el artículo, junto con los

26 "Artículo 111: El suelo con todas sus riquezas, será sometido a un estatuto legal capaz de impedir todo abuso y dar a cada familia de la Ciudad Libre la posibilidad de crearse un hogar familiar, o aquellas que han recibido una formación agrícola profesional, un dominio familiar, asegurados a sus fines de una manera duradera. En esta legislación referente a los hogares familiares se tendrá particularmente en cuenta las familias numerosas, los enfermos de guerra y los inválidos de trabajo. La plusvalía inmerecida que se produjo sobre un bien raíz sin gasto de trabajo ni de capital debe aprovechar a la comunidad.

Artículo 112: La empresa económica privada puede, en virtud de una ley especial y contra indemnización, ser transferidas al dominio público en la medida en que el interés común lo demande”.

27 "Dada la importancia de la tierra para la vida de la Nación y del Estado, la ley podrá someter su comercio a cierta restricciones. Las leyes determinarán la medida en la cual el Estado tiene derecho a proceder a la retroventa forzada de la tierra y regular el traspaso inspirándose en el principio de que la escritura agraria de la República de Polonia debe ser fundadas sobre unidades agrícolas capaces de suministrar una producción normal y que constituyan la propiedad individual de los ciudadanos".

28 "Artículo 153 inciso 4: 'La propiedad obliga".

29 "Artículo 37: La propiedad privada se garantiza.También implica obligaciones. No puede hacerse uso de ella en perjuicio de los intereses de la comunidad. La ley determina su contenido, naturaleza, extensión y límites".

${ }^{30}$ La Constitución Mexicana de Querétaro, en su artículo 27 consagró que "la propiedad de la tierra y aguas comprendidas dentro de los límites del territorio nacional, corresponde originariamente a la $\mathrm{Na}-$ ción, la cual ha tenido y tiene el derecho de trasmitir el dominio de ellas a los particulares, constituyendo la propiedad particular." En el segundo inciso señaló: "La Nación tendrá en todo tiempo el derecho de imponer a la propiedad privada las medidas que dicte el interés público, así como el de regular el aprovechamiento de todos los elementos naturales susceptibles de apropiación para hacer una distribución equitativa de la riqueza pública y cuidar su conservación."

${ }^{31} \mathrm{La}$ Constitución de Weimar ofreció la fórmula: "la propiedad obliga. Su uso debe ser servir, al mismo tiempo, para el bien de la comunidad”. Para Loewenstein, con tal disposición "El pilastre fundamental del liberalismo clásico se ha hundido”. Loewenstein, Karl. Teoría de la Constitución. Barcelona: Ariel, 1965, p. 400. 
relativos a la cuestión religiosa, que provocó más largas discusiones"y constituyó "uno de los puntos de trasformación radical en nuestro derecho". ${ }^{32}$

Respecto del contenido del artículo 10, sostuvo este último autor que

Analizado el artículo serenamente, no consigna sino la regla general de respeto a la propiedad — no ya como derecho absoluto sino como función social—y a los derechos adquiridos, y la excepción: en caso de conflicto entre la necesidad pública reconocida en la ley y el interés privado, éste debe ceder a aquélla; por eso se puede expropiar la propiedad privada y sobrepasar el derecho adquirido, con indemnización previa. Y luego la excepción de la excepción: no habrá indemnización sino por razones de equidad. Y temeroso el constituyente de que pudiera proceder sin prudencia para decretar esto último, puso la traba o el obstáculo de la mayoría absoluta de los votos. ${ }^{33}$

Así las cosas, con la enmienda del año 36, se estableció, para la hasta ese entonces intocable propiedad privada una "función social", de ahí, que esta reforma sea conocida como la "reforma social", en lo sucesivo emergería un nuevo concepto, el de "lo social", por ello se habló de interés social o de utilidad pública.

En resumen, en mi opinión, a partir de entonces la propiedad dejó de ser un derecho natural - porque el hombre por ser hombre, era libre y tenía el derecho de ser propietario-, subjetivo - porque era el poder que tenía el hombre para imponer su voluntad respecto de una cosa a las demás voluntades humanas-y absoluto, propiamente arbitrario - porque implicaba el poder de usar, gozar y disponer de una cosa, y el poder de no usar, de no gozar y de no disponer de ella aunque con ello se perjudicara la sociedad-; para convertirse en una situación jurídica, objetiva y ante todo no absoluta, esto último, en la medida en que los gobernantes tenían el deber de obligar a los propietarios a que empleasen sus cosas en beneficio de la sociedad; así, como un desarrollo de lo expuesto en el numeral precedente, respecto de las obligaciones que se imponen a los gobernados y a los gobernantes, en el sentido en que cada uno tiene una tarea que realizar, una función que cumplir, que, el dominio, desde 1936, tiene una connotación social, teoría expuesta doctrinalmente por León Duguit.

\footnotetext{
32 Gnecco Mozo. Op. cit., p. 144 y ss.

${ }^{33}$ Ibid., p. 148 y ss.
} 
Diego López Medina, al describir la posición del jurista de la época, J.J. Gómez, señala cómo para este último,

La propiedad en la reforma constitucional, no era un derecho, sino una función social. Este cambio definicional amenazó el status quo en el siguiente sentido: el énfasis radica en que los propietarios tienen fundamentalmente deberes, y no tanto derechos frente al colectivo como ocurría en el derecho liberal clásico. En consecuencia la propiedad productivamente subexplotada que se concentra en los latifundios puede ser redistribuida a los campesinos desposeídos. ${ }^{34}$

Un nuevo cuadro comparativo entre el texto de la reforma y un comentario sobre otro colombiano exponente de las tesis solidaristas ayudarán en la explicación:

Tabla 2. Reforma constitucional de 1936 vs. teorías de León Duguit

\begin{tabular}{|c|c|}
\hline Acto Legislativo $\mathrm{n}^{\circ} 01$ de 1936 & $\begin{array}{c}\text { "Las teorías de León Duguit" } \\
\text { Marco Naranjo López }\end{array}$ \\
\hline $\begin{array}{l}\text { Artículo } 10 \text {. Se garantizan la propiedad privada y } \\
\text { los demás derechos adquiridos con justo título, con } \\
\text { arreglo a las leyes civiles, por personas naturales o } \\
\text { jurídicas, los cuales no pueden ser desconocidos ni } \\
\text { vulnerados por leyes posteriores. Cuando de la apli- } \\
\text { cación de una ley expedida por motivos de utilidad } \\
\text { pública o interés social, resultaron en conflicto los } \\
\text { derechos de particulares con la necesidad reconoci- } \\
\text { da por la misma ley, el interés privado deberá ceder } \\
\text { al interés público o social. } \\
\text { La propiedad es una función social que implica } \\
\text { obligaciones. } \\
\text { Por motivos de utilidad pública o de interés social } \\
\text { definidos por el legislador,podrá haber expropiación, } \\
\text { mediante sentencia judicial e indemnización previa. } \\
\text { Con todo, el legislador, por razones de equidad, } \\
\text { podrá determinar los casos en que no haya lugar, a } \\
\text { indemnización, mediante el voto favorable de la ma- } \\
\text { yoría absoluta de los miembros de una yotra Cámara. }\end{array}$ & $\begin{array}{l}\text { La función social impone al individuo la obliga- } \\
\text { ción de emplear su actividad en todo aquello que, } \\
\text { aprovechando así mismo redunde en beneficio de } \\
\text { todos. No es solo la obligación de respetar la acti- } \\
\text { vidad de los demás, sino que, además, le impone el } \\
\text { deber de contribuir al bienestar general con el ejer- } \\
\text { cicio de su actividad física, intelectual y moral. No } \\
\text { tiene derecho de permanecer ocioso. Está obligado } \\
\text { a obrar, en cuanto se lo permitan sus fuerzas. Todo } \\
\text { acto ejercitado por el individuo y que contribuya a } \\
\text { la realización de la interdependencia será protegido } \\
\text { socialmente y de la misma manera será reprimido } \\
\text { toda actividad que perjudique la sociedad. }\end{array}$ \\
\hline
\end{tabular}

Fuente: Elaboración propia con base en el Acto Legislativo de 1936 y texto de Marco Naranjo L.

${ }^{34}$ López Medina, Diego. Teoría impura del derecho. La transformación de la cultura jurídica latinoamericana. Bogotá: Legis, 2012, p. 326 y ss.

${ }^{35}$ Naranjo López. Op. cit., p. 160. 
La nueva realidad constitucional se vio reflejada en el ordenamiento jurídico con la expedición de la Ley 200 de 1936, denominada Ley de Reforma Agraria, que desarrolló la función social del dominio y cuya finalidad principal fue la de otorgar el marco jurídico que sirviera al Estado para adelantar las políticas públicas encaminadas a la distribución equitativa de la tierra y la correcta explotación de los terrenos rurales, y otorgarle instrumentos para hacer cumplir estos objetivos, entre los cuales, los más destacados fueron la enajenación voluntaria, la expropiación y la extinción del dominio. ${ }^{36}$

\section{El intervencionismo social de Estado, los servicios públicos y su aplicación real en la década de los treinta}

Como dice Duguit, no solamente hay cosas que el Estado no puede hacer, sino que también hay otras que el Estado está obligado a hacer [...] y en una palabra a intervenir para procurar el bienestar común, como expresión de un sentido total de la vida humana y no del egoísmo individual. Tulio Enrique Tascón ${ }^{37}$

La Declaración francesa de los Derechos del Hombre y del Ciudadano resumió con sus ideales el ideario de la no intervención, al defender la libertad, la igualdad, la fraternidad y la propiedad como libertades públicas que implicaban para el Estado obligaciones de no hacer, es decir, de no intervención. ${ }^{38}$

No obstante, al descansar el sistema social y el productivo de este modelo de Estado sobre las bases del laissez faire, se profundizaron las desigualdades haciéndose sentir voces detractoras del sistema burgués, ${ }^{39}$ las que le atribuían

${ }^{36}$ El influjo de esta esta concepción de la propiedad se reflejó en el ordenamiento jurídico con la expedición de variadas leyes que desarrollaron la función social de la propiedad en diferentes ámbitos, además de la Ley 200 de 1936, se destacan también la Ley 135 de 1961 "Sobre reforma social agraria", la Ley 9 de 1989, más conocida como la Ley de Reforma Urbana, y por supuesto en el texto constitucional de 1991.

${ }^{37}$ Tascón, Tulio. Derecho constitucional... Op. cit., p. 71.

${ }^{38}$ Malagón Pinzón, Miguel. Vivir en policía. Bogotá: Universidad Externado de Colombia, 2007, p. 22.

${ }^{39}$ Se destacan los socialistas utópicos o premarxistas quienes "fueron un conjunto de pensadores que dan origen filosófico al socialismo como doctrina política y económica, los cuales pueden situarse mayoritariamente en la primera mitad del siglo xIx. Fueron un movimiento diverso que promulgaba la igualdad humana, luchaba por el establecimiento de los valores de la fraternidad social y criticaba los 
haber engendrado injusticia social y exclusión. En efecto, las clases económicamente desfavorecidas llenas de aspiraciones, hicieron ver la tensión existente entre el impulso del hombre a desarrollar libremente su personalidad y las necesidades de una existencia colectiva. Es así como los menospreciados lucharon por la reivindicación de sus derechos y plantearon la erradicación del Estado liberal-burgués, modelo de Estado en el que la exaltación de la autodeterminación individual frente a las intervenciones del Estado habían favorecido los intereses de una clase social: la burguesía. Por su parte, la clase trabajadora sometida económicamente a las fluctuaciones de las coyunturas ocasionadas por un sistema de oferta y demanda con sus crisis, agobiada por el hambre y la miseria, las enfermedades, la incapacidad de trabajo por la edad y el azote del paro laboral, no se contentó con la mera teoría de la libertad y la igualdad contenida en las Constituciones de la época y el catálogo de derechos fundamentales, lo que resultó ser una mera abstracción sin valor pues la realidad demostraba que la plutocracia era la que dominaba el proceso económico y por ende el poder político. Siguiendo a Karl Loewenstein diremos que "Las vacías fórmulas de libertad e igualdad tenían que ser rellenadas con el contenido material de unos servicios públicos que garantizasen a las clases bajas un mínimo de seguridad económica y justicia social". ${ }^{40}$ En ese orden de cosas, se requerían con premura servicios públicos y medidas legislativas político-sociales para protegerse de los males precedentemente descritos, donde se da un replanteamiento de la razón de ser del Estado, orientándose al reconocimiento de su cada vez mayor intervención en la vida social y política; los Estados empezaron a asumir la función de planificar, regular, dirigir, controlar y supervisar la vida socioeconómica, comenzando de este modo el siglo xx con el abandono del modelo liberal puro y el posicionamiento de un paradigma intervencionista, en Colombia también se replicaría este efecto.

abusos de poder de la nueva industria. El socialismo utópico es parte de un proceso dialéctico que enfrenta la industrialización y justifica la liberación humana de las cadenas de la producción a gran escala [...] Dentro de los principales exponentes de este movimiento reivindicador de derechos contra el abuso del capitalismo salvaje están: Claude Saint-Simon, Robert Owen, Charles Fourier y Pierre Proudhon". Castro Urrego, Cristian Darío. Las ideas políticas y el pensamiento administrativo en la historia. Bogotá: Universidad Externado de Colombia, 2012, p. 231. Posteriormente hará su aparición el marxismo liderado por Carlos Marx y Federico Engels.

40 Loewenstein. Op. cit., p. 399. 
En suelo colombiano, a lo largo del siglo xix, el ordenamiento jurídico y los intelectuales mayoritariamente favorecían las ideas del no intervencionismo estatal, por ejemplo, el jurista y Procurador General, don Florentino González (1805-1874) admitía en sus escritos las libertades absolutas, ${ }^{41}$ en consecuencia con ello era partidario de abolir "toda injerencia del gobierno en negocios que no necesitan ser manejados por él; defenderemos las libertades municipales, la libertad de enseñanza, la libertad religiosa, la libertad comercial e industrial; $y$ con las armas de la razón que son las únicas de que haremos uso, combatiremos cuanto contraríe las libertades". ${ }^{42}$ Es más, durante su ejercicio como Secretario de Hacienda en la administración de Tomás Cipriano de Mosquera (1845-1849), es don Florentino ${ }^{43}$ el autor o coautor de la política de librecambio adoptada y que, en sentir de algunos escritores, ${ }^{44}$ tuvo un impacto devastador en la economía artesanal o de subsistencia que el país tenía, en tanto la producción interna de alimentos y artesanías no pudo hacer frente a la ruinosa competencia de las manufacturas importadas de Europa. Como resultados, los artesanos se movilizaron contra el gobierno y empezaron a organizar los primeros sindicatos en la historia nacional, las llamadas sociedades democráticas que jugarían un papel decisivo en la arena pública en los años por venir.

Así se da inicio al tránsito hacia un intervencionismo de Estado proceso que culminó con la expresa consagración de la intervención de Estado en los frentes social y económico en la reforma del 36. Gerardo Molina (1906-1991), miembro del Congreso Constituyente de 1936, en su obra Las ideas liberales en Colombia, acota que

${ }^{41}$ Lo mismo se predica de juristas de la época como Antonio del Real y Cerbeleón Pinzón. La obra de estos ilustres puede consultarse en el tomo I de la compilación de la Cámara de Representantes y el Instituto de Estudios Constitucionales Carlos Restrepo Piedrahíta, Derecho Constitucional Colombiano siglo xIx, Bogotá: Imprenta Nacional de Colombia, 1998.

42 GonzÁLEz, Florentino. Escritos políticos, jurídicos y económicos, Bogotá: Biblioteca Básica de Cultura, 1981, p. 133 y ss.

${ }^{43}$ Datos biográficos de Florentino González pueden leerse en el tomo II Cámara de Representantes y el Instituto de Estudios Constitucionales Carlos Restrepo Piedrahíta, Derecho Constitucional Colombiano siglo xIx, Bogotá: Imprenta Nacional de Colombia, 1998.

${ }^{44}$ Urrutia, Miguel. Historia del sindicalismo en Colombia, citado por Valencia Villa. Op. cit., p. 153 . 
[...] la Constitución de 1886 establecía en el artículo 44 la inspección de las industrias en lo relativo a la moralidad, la seguridad y la salubridad públicas y disponía que la ley podría exigir títulos de idoneidad para el ejercicio de las profesiones médicas y auxiliares. El Acto legislativo no 1 de 1918, avanzó más al disponer que la ley podrá ordenar la revisión y fiscalización de las tarifas y reglamentos de las empresas públicas y de transporte, y que se deberá exigir títulos de idoneidad para el ejercicio de la abogacía. El Acto Legislativo no 1 de 1921, prescribió a su turno que la ley podrá restringir la producción y el consumo de los licores y las bebidas fermentadas.

Otro ejemplo de intervencionismo, antes de la reforma de 1936, fue la Ley 45 de 1923 sobre superintendencia y banca.

Lo que sucede es que a partir de ese año 36 se institucionaliza en nuestro país la intervención estatal, entendida esta en sentido amplio y no exclusivo de la vida económica del país, ${ }^{45}$ pero, adicionalmente, se le agrega un elemento distintivo: la dimensión social, lo que explica que el prestigio del intervencionismo se dé en Colombia con la reforma de López Pumarejo, ${ }^{46}$ cambio que no aparece por casualidad sino como un reclamo histórico:

${ }^{45} \mathrm{El}$ intervencionismo propuesto por López Pumarejo no se circunscribía estrictamente al campo económico, sino que se extendía a la regulación de otros aspectos de la vida social como el educativo. En este último punto sí que plantearía problemas pues, de acuerdo al Concordato, a la Constitución de 1886 y a la política de gobiernos conservadores, era la Iglesia católica la que conducía la educación y frente a ello el Estado estaba sometido, por lo que cualquier tipo de intervención en esta área era, a los ojos del clero, indebida. Por ello, cuando López planteó una reforma al sistema educativo, los obispos y el Partido Conservador hicieron sentir su reparo llamando prácticamente a la desobediencia y a la rebelión. Planteaba el Presidente la necesidad de la vigilancia oficial en materia educativa, sin perjuicio de que esta fuera en el régimen privado católica o confesional, y sin que fuera estrictamente laica en lo público y le suprimiera prerrogativas al clero.

${ }^{46}$ López Pumarejo deja ver su posición sobre la intervención del Estado en los mensajes presidenciales de los años 1935 y 1936. En el primero, muestra su percepción de dos sectores sociales frente al intervencionismo, señalando que, de un lado, se encuentra la joven izquierda partidaria de una intensa intervención y, de otro, los industriales seguidores en algunas ocasiones del intervencionismo de Estado como cuando se trata de favorecerlos en sus actividades con altos derechos de aduana, pero adversos a ella cuando se debe intervenir para defender a los trabajadores en sus relaciones obrero-patronales. En el Mensaje al Congreso en 1936 acentúa en su idea de no reducir el intervencionismo al ámbito de lo estrictamente económico y les recuerda a los industriales que no pueden aceptar y rechazar la intervención del Estado conforme a sus intereses. Por último, enfatiza allí en la necesidad del Estado de intervenir para regular los conflictos del trabajo. 
Los importantes cambios sociales y económicos que trajo el siglo $\mathrm{xx}$, entre otras razones por las altas sumas de dinero que ingresaron a la nación producto de la exportación del café, el pago de los dineros correspondientes a la indemnización por la pérdida del canal de Panamá, los préstamos otorgados a nuestro país por el gobierno norteamericano, ocasionaron, por un lado, un crecimiento del capital y, a la vez, un desarrollo del tema sindical y social en Colombia, tanto así que para la última administración de la denominada República Conservadora (comprendida entre 1926 y 1930) la crisis social, económica y política abrumaba: huelgas obreras, motines estudiantiles, más la fuerte oposición liberal condujeron a la victoria de este partido en la siguiente elección presidencial (con Enrique Olaya Herrera), quien permaneció en el poder durante el decenio de 1930 a 1940.

El texto en la enmienda del 36 sobre intervencionismo es el siguiente:

Artículo 11. El Estado puede intervenir por medio de leyes en la explotación de industrias o empresas públicas y privadas, con el fin de racionalizar la producción, distribución y consumo de las riquezas, o de dar al trabajador la justa protección a que tiene derecho.

De la norma se desprende, en primer lugar, que se trata de la institucionalización de la intervención del Estado en nuestro país, adicionalmente, que la intervención es facultativa y no obligatoria, es decir que se trata de la atribución de una potestad del Estado.

Se colige también que la facultad interventora debe hacerse por mandato de la ley, esto es, la condición de posibilidad será la mediación de un mandato legal. Se establece así una prudente limitación a la intervención: "que no sea el gobierno el intervencionista por su propia iniciativa, sino que lo haga en ejercicio de leyes expresas; y que estas tengan el mismo respaldo de opinión que se exige para las expropiaciones sin indemnización, es decir, mayoría absoluta de votos en ambas Cámaras". ${ }^{47}$ Igualmente, la intervención del Estado en la economía opera respecto de los sectores público y privado; por último, la parte concluyente de la disposición, la finalidad social: intentar corregir la desigualdad entre los trabajadores y los propietarios de los medios de producción, la protección de un sujeto(s) en situación de necesidad. Al decir de

${ }^{47}$ Gnecco Mozo. Op. cit., p. 176. 
Gnecco Mozo, "el legislador halla en la nueva constitución puerta abierta para establecer todas las reformas sociales; fijar salarios máximos, auxilios de retiro, jubilaciones, seguros, medidas de higiene y participación del obrero en los beneficios". 48

Se advierte entonces, en primer lugar, el nuevo rol del Estado, no como poder soberano, sino para servir, los gobernantes para servir a los gobernados, es decir, ejerciendo una función social. Leyendo a Duguit: "Los hombres políticos dignos de este nombre están de acuerdo en reconocer que se ha producido un gran cambio en la noción del Estado; que el Estado no tiene solamente el derecho de mandar, sino que tiene también grandes deberes que cumplir". ${ }^{49}$ Adicionalmente, supone la disposición un Estado activo, según Duguit, al Estado incumbe, en efecto, el deber de hacer todas aquellas actividades y procurar todos aquellos servicios que sean necesarios para garantizar la protección y el bienestar de los individuos: en esta dirección de política legislativa se sitúa o inserta la legislación positiva moderna. ${ }^{50}$

De este modo, el Estado interviene para la prestación de los servicios públicos entendidos estos últimos como "una obligación de orden jurídico que se impone a los gobernantes, es decir a aquellos que de hecho tienen el poder en un país dado, obligación de asegurar sin interrupción el cumplimiento de una cierta actividad". ${ }^{1} \mathrm{Y}$ más adelante señala el autor: "Por consiguiente, a medida que la civilización progresa la intervención de los gobernantes va siendo normalmente más frecuente". ${ }^{52} \mathrm{La}$ intervención se justifica además, para garantizar la permanencia y continuidad de los servicios públicos.

En resumen, considero que la visión del derecho social de Duguit cambió, en nuestro país, el entendimiento de las libertades individuales, en especial la sacrosanta propiedad privada y el aparato estatal, pues este último desde entonces

${ }^{48}$ Ibid., p. 178.

${ }^{49}$ Las transformaciones del derecho (Público y privado), tr. Adolfo Posada y Ramón Jaén. Buenos Aires: Heliasta, p. 29.

${ }^{50}$ Duguit, León, Manual de derecho constitucional. Teoría general del Estado. El derecho y el Estado. Las libertades públicas. Organización política. Madrid: Francisco Beltrán, 1926, p. 277 y ss.

${ }^{51}$ Carlos H Pareja define en su obra, siguiendo la tesis duguitiana, el servicio público: "Concretamente considerado, el servicio público es la actividad del Estado, ejecutada directamente o por medio de concesionarios, encaminada a satisfacer las necesidades de interés general en forma regular y continua". Pareja. Op. cit., p. 105.

${ }^{52}$ Duguit, Las transformaciones... Op. cit., p. 29 y ss. 
es asegurador de la organización y funcionamiento de los servicios públicos. El cambio de modelo en la prestación de los principales servicios públicos en el país, de un esquema regido por los privados a uno guiado por el Estado, primordialmente a través de los municipios, demuestra esta aseveración. A continuación se desarrolla esta idea:

La prestación de los servicios públicos de acueducto, alcantarillado y aseo en Colombia ha sido clasificada por la doctrina nacional ${ }^{13}$ en cuatro períodos: Entre 1875 y 1930, entre 1930 y 1950, entre 1950 y 1990 y después de 1990. "Esta subdivisión caprichosa obedece a tres criterios: el grado de intervención del Estado, los mecanismos de financiación y la propiedad de las empresas" ${ }^{54}$

$\mathrm{Al}$ primer período se le suele denominar "Modo privado de suministro de servicios", 55 toda vez que desde los inicios de la temática en el año 1875 y hasta 1930 la prestación, rudimentaria además, ${ }^{56}$ estuvo a cargo de privados mediante contratos de concesión de los municipios, operaban así los acueductos en Barranquilla (1880), Bogotá (1886), Medellín (1891), Cartagena (1905) y Pereira (1918). ${ }^{57}$ En cuanto al servicio de energía eléctrica ocurría algo similar, "En 1888 se crea en Bogotá la Electric Light Company, fundada por el general Pedro Nel Ospina, y en 1895 se constituye en Medellín la Compañía Antioqueña de Instalaciones Eléctricas, empresa mixta con capital privado mayoritario. Es igualmente privada la primera empresa de distribución de electricidad de Cali, llamada Empresa de Luz y Energía”. ${ }^{58}$ En materia de aseo "según los registros históricos, en 1874 Bogotá contrata con empresas privadas la recolección y transporte de residuos sólidos en vehículos de tracción

${ }^{53}$ Sobre el particular pueden revisarse las obras de JaRAMILLO, Samuel. Ciento veinte años de servicios públicos en Colombia. Bogotá: cinep, 1995; AMAdor CABRA, Luis Eduardo. los servicios públicos frente a las reformas económicas en Colombia. Bogotá: Editorial Universidad Externado de Colombia, 2011.

54 Amador Cabra. Op. cit., p. 52.

55 Ibid., p. 53.

56 "Los pocos servicios que comenzaron a prestarse, alumbrado público a gas, el acueducto por tuberías de hierro sin tratamiento, energía eléctrica de generación hídrica y térmica, la telefonía y el aseo, eran precarios, rudimentarios", Colombia. Ministerio de Justicia y del Derecho, Unidad de Investigaciones Jurídico Sociales -unijus-. Bogotá: Imprenta Nacional de Colombia, 1997.

${ }^{57}$ Betancourt, Luis Ignacio. Avances y perspectivas de la regulación de los servicios de agua potable y saneamiento básico. Informe presentado a la CRA, Bogotá, agosto 1998, p. 7, citado por AMADor, Cabra. Op. cit., p. 52.

${ }^{58}$ Vélez Álvarez, Luis Guillermo. Diez años de regulación de servicios públicos domiciliarios, Lo bueno, lo malo y lo feo de un modelo mestizo. En: Lecturas de Economía, enero-junio 2006, nº 64.p. 147. 
animal y para 1892 cuenta con 58 carros de caballos que recogían la basura puerta a puerta. En Medellín se sabe que existían contratos con particulares para la misma labor desde 1874 con una técnica similar".

Frente a tal situación, el papel de la nación era prácticamente nulo y la capacidad reguladora de los municipios, débil, especialmente en lo relacionado con tarifas y coberturas. En ello tiene que ver la ausencia de políticas administrativas frente a su prestación producto de la ideología del laissez faire y la debilidad de los fiscos municipales que les impedía asumir esta tarea de manera directa.

En suma, el período de 1875 a 1930 se caracterizó por la escasa capacidad reguladora del Estado, puesto que el papel de la Nación no existía y los prestadores en los municipios eran empresas privadas asociadas con capital extranjero que funcionaban bajo concesión otorgada por el ente territorial. Un elemento característico del período es que fue el mercado el que desarrolló las primeras infraestructuras de servicios públicos y no el Estado. ${ }^{59}$

No obstante, el esquema produjo tensiones, en primer lugar, porque los servicios estaban dirigidos a sectores de la población que podían generar a las empresas particulares lucro con su prestación, circunstancia que propició el fenómeno de la prestación clasista o de élite en servicios que por su naturaleza debían llegar sin distinción a todos los sectores de la población. De hecho, "hasta este momento, los servicios públicos, y en particular los domiciliarios, no tenían la connotación social de hoy; por el contrario eran asumidos en condiciones suntuarias, costosas y, por tanto, de difícil acceso". 60

A esto se suma la incapacidad o ausencia de interés de parte de las compañías prestadoras de los servicios públicos para expandir la cobertura en la medida en que la demanda se ensanchaba; por el contrario,

[...] los niveles de los servicios descendían (congestión y disminución en la frecuencia de los tranvías, daños permanentes por falta de mantenimiento y deficiencias en la depuración en el acueducto, cortes y

\footnotetext{
${ }^{59}$ Amador Cabra. Op. cit., p. 54.

${ }^{60}$ Colombia. Ministerio de Justicia y del Derecho, unijus. Op. cit., p. 26.
} 
racionamiento en la electricidad, etc.), y al mismo tiempo, las tarifas se elevaban: esto hacía especialmente irritantes estas tensiones. Por ello, se acumulan fricciones con las compañías prestatarias de los servicios y comienza a tomar cuerpo en la opinión de los habitantes una insatisfacción generalizada, y una aspiración, que toma la forma de presión política, de buscar un mecanismo alternativo que substituyera a los contratistas privados. ${ }^{61}$

De ello daba cuenta el intelectual liberal Alejandro López I. C., en su obra Idearium liberal, escrita en 1929, pero publicada solo hasta 1931, cuando señalaba cómo ese descontento nacional reinante respecto de la prestación de los servicios por los privados orientaba la tendencia hacia el dominio público de los mismos. La ineficiencia en la prestación (demoras, prórrogas, mal servicio) y la mala fe de los empresarios fueron las principales causas de la inconformidad. En palabras de López:

Por si las enseñanzas de nuestra historia ferrocarrilera no fueren suficientes para reforzar la tendencia inconscientemente 'estatista' de nuestra ciudadanía, podemos volver los ojos a las empresas municipales de servicios públicos, comenzando por el tranvía de Bogotá, siguiendo con la concesión de energía eléctrica de Medellín, con todos los incidentes que obligaron a la totalidad de los contribuyentes de mi ciudad natal a no tolerar empresas particulares en ningún servicio público; y sin dejar que las desventuras del manejo de las empresas oficiales de Bogotá, pasajeras y tolerables, nos obscurezcan el sentido hasta olvidar los incidentes del Teléfono de esa ciudad. Cartagena y Barranquilla, Cali y Manizales podrían también aportar a la discusión casos pertinentes que explicarían la marcada tendencia de todas esas ciudades a la propiedad pública en los servicios públicos, agua, energía, tranvías y teléfonos, ferias y mercados (Resaltado fuera de texto). ${ }^{62}$

De allí que en su Idearium liberal, la propuesta de López (Alejandro) respecto de los servicios fuera contundente: la estatización de los mismos, aludía

\footnotetext{
${ }^{61}$ Jaramillo. Op. cit., p. 40.

${ }^{62}$ López I. C., Alejandro. Idearium liberal. Medellín: Marín Vieco, 1997, p. 286.
} 
concretamente a "la necesidad de construir, explotar y administrar por cuenta del Estado todas las empresas de producción y venta de servicios públicos, con exclusión del interés particular" ${ }^{63}$ No obstante, el fundamento teórico de tal planteamiento lo encontraba López en el inglés John Maynard Keynes; no creemos que Duguit hubiese ejercido influencia directa sobre él, por lo menos en su Idearium no hay referencia alguna al profesor francés, no obstante, resulta importante mostrar cómo con fundamento en distintos trabajos de autores extranjeros se propugnaba por la estatización de los servicios, por la adopción de un nuevo modelo del Estado frente a los servicios públicos.

Así las cosas, ante la crisis de la prestación de los servicios por los particulares, lo esperable era entonces que los organismos estatales pudieran suministrar estos servicios sin otro objetivo que el de satisfacer las necesidades de la población, se destacan las, entonces denominadas, empresas públicas municipales, creadas "para administrar los servicios de mercado, matadero, teléfonos, feria de ganados, acueducto, energía eléctrica y tranvía municipal”. ${ }^{64} \mathrm{El}$ referido Alejandro López I. C. señalaba precisamente respecto de las Empresas Públicas Municipales de Medellín cómo estas se superponían a la fatal sentencia de Adam Smith cuando declaró malos administradores a todos los gobiernos de todos los tiempos. Al decir de López:

No se necesita emplear el esmeril del patriotismo o del optimismo para alisar rugosidades a fin de poder declarar que hay empresas oficiales, como las Empresas Públicas Municipales de Medellín, el Ferrocarril de Antioquia o el de Caldas, así como la construcción por cuenta de la Nación del Ferrocarril del Pacífico, cuya eficiencia iguala y aun supera la eficiencia de las empresas privadas. ${ }^{65}$

En concordancia, a partir de la década de los treinta y hasta mediados de siglo, la prestación de los servicios públicos estuvo a cargo de los municipios y la nación tenía la obligación de financiarlos, pasó entonces el país, en materia de prestación de servicios públicos, de un modelo liderado por el

\footnotetext{
${ }^{63}$ Ibid., p. 327.

${ }^{64}$ VéLez Álvarez, Luis Guillermo. ¿Tienen futuro las empresas públicas en la provisión de los servicios públicos? En: Ensayos de economía, Universidad Nacional de Medellín. Vol. 4, núm. 6, 1993, p. 17.

${ }^{65}$ López I. C. Op. cit., p. 287.
} 
sector privado a una intervención del Estado dirigida en la mayor parte por los municipios o, mejor, a lo que la doctrina ha denominado "modo centralista de la prestación". ${ }^{66}$

La reforma constitucional impulsada por el gobierno de López Pumarejo, de la que hemos venido hablando y que introdujo cambios significativos en el papel del Estado, al asignarle a este un rol intervencionista y activo frente a la problemática social y económica de la población, generó efectos inmediatos en la política y manejo de los servicios públicos, de allí que las autoridades administrativas, en especial las locales se vieron avocadas a la prestación de los servicios públicos a partir del esfuerzo propio y con cargo a sus limitados presupuestos públicos.

Justamente con fundamento en esta nueva concepción intervencionista del Estado colombiano se expidieron ante la crisis de los servicios públicos las Leyes 65 y 109 de 1936, disposiciones que constituyeron el inicio en Colombia de la concepción administrativa de los servicios públicos, en la medida en que delinearon las responsabilidades nacionales y locales en la materia. La primera estuvo evidentemente influenciada por la escuela del servicio público francesa en la medida en que en ella se dispuso como esencial la intervención del Estado como garante y prestador del servicio público de agua potable. No establece que sea el Estado central quien entre de manera directa a prestar este servicio, sino que plantea una división de competencias entre diferentes agentes estatales que puede resumirse así:

La responsabilidad directa en la prestación del servicio y su gestión es asignada a los municipios a los que se les divide en categorías, de acuerdo a su población, menores y mayores de veinte mil habitantes, los primeros recibían ayuda financiera de la nación y del departamento al que pertenecieran para la construcción de su sistema de acueducto; los más grandes debían financiar su infraestructura con recursos propios o con préstamos, pero en todo caso la prestación de los servicios estaría a cargo de los municipios. Al departamento se le encargó la labor de contribuir con la financiación de la construcción de los acueductos, adicionalmente, la de realizar los estudios técnicos necesarios.

Por su parte, la nación debía participar en la construcción de las obras, podía auspiciar hasta el 50\% de los costos de construcción en los municipios pequeños. En el caso en que fuese el mayor aportante dirigir su construcción;

${ }^{66}$ Amador Cabra. Op. cit., p. 55. 
en todo caso debía supervigilarlas a través de la oficina encargada del Ministerio de Obras Públicas. A la nación también le correspondería a través del citado ministerio el control de las tarifas, con el objeto de que "no sean tan altas que perjudiquen los intereses de los consumidores, ni tan bajas que no den los productos necesarios para el sostenimiento, reparación, conservación y mejora de las obras". 67

Del contenido de lo expuesto se infiere entonces que el tipo de intervención que planteó la disposición por parte de la nación es de fomento (asistencia en la construcción), y la del municipio es la prestación (responsabilidad directa del servicio y su gestión). En últimas, "la Ley 65 transformó la acción estatal en el sector de agua potable, dio al Estado funciones acordes con su nuevo rol y responsabilidad directa a los municipios; creó un Fondo con aportes de los Departamentos y la Nación para el suministro de agua potable y estableció la vigilancia de la Nación a través del Ministerio de Obras Públicas". ${ }^{68}$

La Ley 109 se ocupó de la regulación de las tarifas en materia de servicios públicos de energía y acueducto, fue esta disposición más tímida en los alcances de la intervención estatal. "Su conclusión es la de asegurar el control de su operación por parte del gobierno central, con el punto notable de hacer depender las tarifas cobradas de la autorización gubernamental". ${ }^{69}$

Con posterioridad, leyes como la 107 de 1938 y 126 de 1938 reforzarían el mandato intervencionista del Acto Legislativo no 01 de 1936 para los servicios de alcantarillado y telefonía, respectivamente. Sostiene Samuel Jaramillo que será el servicio público de transporte el que se alejará de esta tendencia, "En efecto, en esta época en que la tendencia global es hacia un mayor involucramiento del Estado, en la prestación de los servicios urbanos y hacia su municipalización, el transporte urbano va a seguir una trayectoria inversa: de una situación inicial en las grandes ciudades de monopolio de empresas municipales se va a ir cediendo esta actividad de manera paulatina a agentes privados"..$^{70}$ Sin embargo, "la incorporación de la gestión estatal central en los servicios públicos domiciliarios, los problemas de cobertura y financiación no fueron resueltos; la demanda domiciliaria e industrial siguió

\footnotetext{
${ }^{67}$ Jaramillo. Op. cit., p. 48.

${ }^{68}$ Colombia. Ministerio de Justicia y del Derecho, unijus. Op. cit., p. 27.

${ }^{69}$ Jaramillo. Op. cit., p. 49.

${ }^{70}$ Ibid., p. 62.
} 
creciendo a un ritmo mayor que la oferta y el desbalance con el sector rural fue cada vez más crítico". ${ }^{71}$

Puede mostrarse hasta aquí el papel interventor del Estado en la prestación de los servicios públicos a partir de los años treinta en Colombia, primordialmente a través de los municipios, planteamiento acorde por completo con lo expuesto, sobre el punto, por otro seguidor de Duguit en este país, el profesor Carlos H. Pareja.

Señalaba Pareja sobre la descentralización, contenida en la entonces vigente Constitución de 1886, que la misma implicaba una autonomía seccional principalmente la municipal, la que tiende a desarrollarse bajo la influencia cada día más persistente de un nuevo criterio en la organización administrativa de los servicios públicos. Sostiene este autor, que "la descentralización es administrativa cuando los servicios públicos se organizan autónomamente del poder central y las secciones en que el estado se divide manejan independientes sus bienes propios". ${ }^{72}$ El municipio, para Pareja (1937), está llamado a convertirse en el centro activo de la vida nacional; en el futuro corresponderá a este dirigir todos los servicios públicos ordinarios, ${ }^{73}$ en lo que se llamará, en su criterio, la municipalización de los servicios públicos. El intervencionismo del Estado moderno se hace notar en los municipios más que en ninguna otra rama de la administración del Estado, es esta entidad territorial la que debe prestar los servicios de transporte públicos, mataderos, mercados, conducción de aguas, distribución de fluido eléctrico, gas, y no concibe que estos queden en manos privadas cuando encajan en la función administrativa. ${ }^{74}$

El fundamento constitucional, según Pareja, para llevar a cabo lo anterior, lo encuentra en el artículo 28 de la que llama la "nueva Constitución" y que no es más que la norma que contiene la intervención del Estado en la economía.

71 Colombia. Ministerio de Justicia y del Derecho, unijus. Op. cit., p. 28.

72 Pareja. Op. cit., p. 82.

${ }^{73}$ Ibid., p. 88.

74 "La municipalización de servicios consiste en que el Municipio asuma directamente la prestación de los servicios, eliminando la dirección privada de ellos. Todavía entre nosotros existen muchos servicios controlados por particulares, que debieran muncipalizarse: por ejemplo, el de funerarias; repugna hacer negocio con los cadáveres, y es triste el espectáculo que en los barrios de gentes pobres ofrecen los entierros; entierro de pobre es una frase que se ha vulgarizado para indicar la indigencia de estos actos. Creemos que ya es tiempo de que los Municipios intervengan en ese y otros servicios públicos, como el de taxis, a fin de muncipalizarlos evitando al público los constantes abusos que con ellos se cometen por los negociantes privados, interesados únicamente en el lucro". Ibid., p. 91. 
En resumen, entre 1930 y 1950 el esquema de servicios públicos se caracteriza por "el tránsito de un modelo liderado por el sector privado a una intervención del Estado dirigido desde el sector central en la mayor por parte de los municipios del país". ${ }^{75}$

De lo expuesto se concluye que a partir de la reforma Constitucional de 1936, el Estado gendarme o policía resulta absolutamente incompatible con el nuevo esquema Estado-individuo-sociedad. El derecho social que involucra la inexistencia de los derechos subjetivos, las nociones de solidaridad y función social requerirán de la intervención del Estado, representante y garante de los intereses de la sociedad, es decir, intervención con contenido social. Existe, entonces, un elemento nuevo en el papel del Estado colombiano a partir de la vigencia de la reforma del 36, y se trata de la cuestión social, que incumbe al Estado, y que comprende especialmente el reconocimiento de determinados deberes sociales y la ampliación de la órbita de acción estatal en favor de la tutela del servicio público. La reforma no involucró una ampliación de los derechos y garantías formales de los ciudadanos, sino una extensión de la órbita de acción estatal a fin lograr la satisfacción de las necesidades tanto individuales como colectivas.

Exactamente cincuenta años luego de sancionada la Constitución de 1886 se promulgó la histórica reforma de 1936, que ha sido el tema central de este análisis. Desde entonces han transcurrido casi 80 años y por ello pensé que sería un buen momento para llevar a cabo una revisión y valoración de lo acontecido, leer textos, ciertamente leídos y releídos por generaciones, redescubrir otros, me llevaron a nuevas apreciaciones e interpretaciones y a una importante resolución: debe reconocerse que la enmienda del 36, aquella que superó para el ordenamiento jurídico colombiano el individualismo puro que durante más de un siglo de vida republicana ejerció su hegemonía, la que desacralizó la propiedad privada, aquella que institucionalizó en Colombia el rol intervencionista del Estado, ensanchando por tanto su radio de acción, recibe en Colombia la teoría de la solidaridad social — suficientemente conocida en la época- expuesta por el profesor francés León Duguit.

75 Amador Cabra. Op. cit., p. 57. 